Research Article

\title{
Experimental and Numerical Analyses of the Rational Loading Waveform in SHPB Test for Rock Materials
}

\author{
Song Luo ${ }^{1}{ }^{1}$ and Fengqiang Gong (D) $^{1,2}$ \\ ${ }^{1}$ School of Resources and Safety Engineering, Central South University, Changsha, Hunan 410083, China \\ ${ }^{2}$ State Key Laboratory of Coal Resources and Safe Mining, China University of Mining \& Technology, Xuzhou, \\ Jiangsu 221008, China \\ Correspondence should be addressed to Fengqiang Gong; fengqiangg@126.com
}

Received 17 August 2018; Accepted 6 November 2018; Published 3 December 2018

Guest Editor: Li Chen

Copyright (c) 2018 Song Luo and Fengqiang Gong. This is an open access article distributed under the Creative Commons Attribution License, which permits unrestricted use, distribution, and reproduction in any medium, provided the original work is properly cited.

\begin{abstract}
Aiming at the determination of the rational loading waveform for rock materials, the comparative impact tests under the loadings of rectangular and half-sine stress waves were performed on red sandstone using an $\varnothing 50 \mathrm{~mm}$ SHPB apparatus. Experimental results with the rectangular stress wave affirm that the waveform dispersion and stress-strain curve oscillation frequently exist during the test of rock materials, which signifies that the accuracy of test results derived from the rectangular stress wave loading cannot be guaranteed. Under the loading of the half-sine stress wave, the phenomenon of wave dispersion during the tests has been eliminated radically, and there is no oscillation in the stress-strain curves. To further demonstrate the rationality of the halfsine wave loading in the SHPB test, by utilizing the three-dimensional numerical simulation approach, the propagations of rectangular, triangular, and half-sine stress waves travelling in the axial and radial directions of the SHPB with four elastic bar diameter sizes are analyzed and compared. The results show that the waveform dispersion of the rectangular and triangular stress waves always exists and will be more and more serious with increasing diameter size and propagation distance. For the half-sine stress wave, the waveform dispersion effect is very weak and not affected by the bar diameter size and propagation distance. The half-sine stress wave is the rational loading waveform for rock SHPB tests with different bar diameters.
\end{abstract}

\section{Introduction}

Rock engineering is often subjected to a lot of dynamic loads (such as blasting, impact, strike, and earthquake) [1]. The dynamic properties of rock materials under dynamic loads are one of their essential attributes and also provide the basic information for the design of underground protection works against blast and impact loadings. It is well known that the split Hopkinson pressure bar (SHPB) has been extensively applied to the investigations on dynamics of rock materials [2-4]. But it is noteworthy that the original SHPB device was primarily invented for the study of metallic materials (the cylindrical specimen is $7-13 \mathrm{~mm}$ in diameter, also processed with small length/diameter ratio), and the rectangular stress wave was adopted for the impact test [5]. Compared with metallic material, the rock material is essentially a solid aggregate that is composed of minerals and other substances and a porous media in structural properties having two main characteristics, the anisotropy and heterogeneity. In the standard static load test, the International Society for Rock Mechanics (ISRM) [6], as well as many testing regulations, recommends that the diameter of a cylindrical rock specimen should be approximately $50 \mathrm{~mm}$ and that of a concrete specimen is suggested to be larger than $70 \mathrm{~mm}$. As a result, the large diameter rock specimen is necessary whilst carrying out the impact test using the SHPB. Recently, many research institutes or universities have been equipped with the SHPB system where the bar diameter is equal or greater than $50 \mathrm{~mm}$, and based on which, numerous correlative researches have also been conducted [7-11]. However, there are several key problems that need to be solved when the conventional rectangular stress wave produced by a 
cylindrical striker is applied on rock materials in the large diameter SHPB test, such as waveform dispersion, stressstrain curve oscillation, and stress equilibrium [12-14]. These problems will result in an inappropriate application of one-dimensional stress wave theory to the large diameter SHPB device. Consequently, for the large diameter SHPB device, it is eager to determine a kind of loading wave that is without dispersion, oscillation, and can well achieve the stress equilibrium conditions during the test, and the halfsine stress wave has been introduced in many experimental researches [7, 15]. However, among these researches, the comparison test for the mechanics and energy characteristics of rock materials under the rectangular wave and half-sine stress wave is relatively few.

In order to compare dynamic properties of rock materials under the rectangular and half-sine stress waves, the impact tests of red sandstone were conducted under the rectangular wave and half-sine stress waves on an $\varnothing 50 \mathrm{~mm}$ SHPB apparatus. Besides, for the characteristics of stress waves travelling in different waveforms, the propagations of rectangular, triangular, and half-sine stress waves in different diameter bars were compared and analyzed by using the three-dimensional numerical simulation method. The experimental and numerical results show that the half-sine stress wave is the rational loading waveform for the rock material SHPB test.

\section{Testing Principle of SHPB}

As shown in Figure 1, in the actual SHPB test [4], a rock specimen is sandwiched between the incident and transmitted bars (the lengths of the incident bar and transmitted bar are 2000 and $1500 \mathrm{~mm}$ ); a striker (in this research, both the cylindrical and spindle-shaped strikers with the same diameter of $50 \mathrm{~mm}$ and the lengths of 410 and $360 \mathrm{~mm}$ were used, respectively), of the same material as the incident bar, flies out under the action of gas pressure and impacts the incident bar, causing a stress pulse $\sigma_{\mathrm{I}}(t)$ to initiate at the loaded end of the incident bar and travel towards the rock specimen. Upon the assumption of one-dimensional stress wave theory, the stress pulse $\sigma_{\mathrm{I}}(t)$, i.e., the incident stress wave, propagates forward with velocity $C_{0}=\sqrt{E \rho^{-1}}$ in the incident bar, where $E$ and $\rho$ are the elastic modulus and density of the bar, respectively. After its arrival at the rock specimen-bar surfaces, the reflective stress pulse $\sigma_{\mathrm{R}}(t)$ and the transmitted stress pulse $\sigma_{\mathrm{T}}(t)$ are generated in the incident and the transmitted bars, respectively. The incident strain signal $\varepsilon_{\mathrm{I}}(t)$ and reflected strain signal $\varepsilon_{\mathrm{R}}(t)$ are measured by the strain gauge $G_{1}$ pasted on the middle of the incident bar and the transmitted strain signal $\varepsilon_{\mathrm{T}}(t)$ by the strain gauge $G_{2}$. Note that the three strain signals measured by the two strain gauges represent those derived from the forces at both ends of the specimen.

According to the measurements of above parameters, the average stress $\sigma_{s}(t)$, strain rate $\dot{\varepsilon}_{s}(t)$, and strain $\varepsilon_{s}(t)$ of the rock specimen can be described by the following formulas [16]:

$$
\left.\begin{array}{rl}
\sigma_{\mathrm{s}}(t) & =\frac{A E}{2 A_{\mathrm{s}}}\left[\varepsilon_{\mathrm{I}}(t)+\varepsilon_{\mathrm{R}}(t)+\varepsilon_{\mathrm{T}}(t)\right], \\
\dot{\varepsilon}(t) & =\frac{C_{0}}{l_{\mathrm{s}}}\left[\varepsilon_{\mathrm{T}}(t)-\varepsilon_{\mathrm{I}}(t)+\varepsilon_{\mathrm{R}}(t)\right], \\
\varepsilon & (t)=\frac{C_{0}}{l_{\mathrm{s}}} \int_{0}^{t}\left[\varepsilon_{\mathrm{T}}(t)-\varepsilon_{\mathrm{I}}(t)+\varepsilon_{\mathrm{R}}(t)\right] d t,
\end{array}\right\}
$$

where $A$ and $A_{\mathrm{s}}$ are the cross-sectional areas of the bar and specimen, respectively, and $l_{\mathrm{s}}$ is the length of the specimen.

For the energy calculation during the test, the absorbed energy $E_{\mathrm{s}}$ of the loaded specimen is expressed as

$$
E_{\mathrm{s}}=E_{\mathrm{I}}-E_{\mathrm{R}}-E_{\mathrm{T}},
$$

where $E_{\mathrm{I}}, E_{\mathrm{R}}$, and $E_{\mathrm{T}}$ are the incident, reflection, and the transmission energies, respectively; they can be obtained by [16]

$$
\left.\begin{array}{l}
E_{\mathrm{I}}=\frac{A}{\rho C_{0}} \int_{0}^{\tau} \sigma_{\mathrm{I}}^{2}(t) d t, \\
E_{\mathrm{R}}=\frac{A}{\rho C_{0}} \int_{0}^{\tau} \sigma_{\mathrm{R}}^{2}(t) d t, \\
E_{\mathrm{T}}=\frac{A}{\rho C_{0}} \int_{0}^{\tau} \sigma_{\mathrm{T}}^{2}(t) d t,
\end{array}\right\}
$$

where $\tau$ is the duration of the stress wave.

\section{Actual Experimental Analyses}

To know about the wave travelling properties in the SHPB test and the responses of rocks under rectangular and half-sine stress waves, we first conducted experiments without specimen for the measurement of waveforms at different positions. Then, experiments on red sandstone were also performed by using the rectangular and half-sine stress waves. As described in Section 2, the rectangular and half-sine stress waves were generated by impacting the incident bar via the cylindrical and spindle-shaped strikers, separately. The physical dimensions of spindle-shaped striker in this research are shown in Figure 2 [15]. When using the striker below, the duration of the half-sine stress waves is approximately 200 microseconds, and the amplitude of the incident stress waveform can be changed by the position of the strikers and applied gas pressure in the pressure vessel. Certainly, the length and shape of strikers would lead to changes in the stress waveform, and the related investigation can be found in [17].

3.1. Test Specimens. The specimens used for the contrast test were extracted from the same red sandstone block. The average longitudinal wave velocity of the red sandstone is $3084 \mathrm{~m} / \mathrm{s}$. The density is $2390 \mathrm{~kg} / \mathrm{m}^{3}$. The rock block was manufactured into specimens with a diameter of $50 \mathrm{~mm}$ and a height/diameter ratio of 1.0. Then, the surfaces of all the specimens were carefully polished such that specimen and 


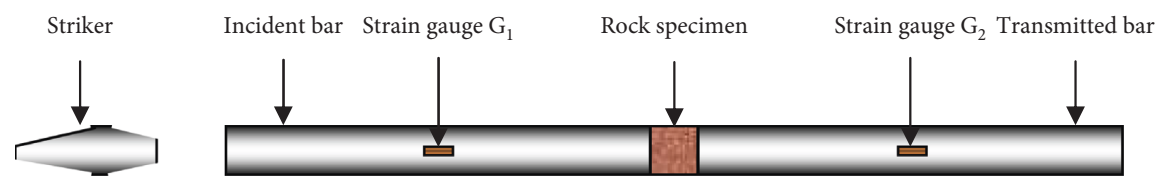

Figure 1: Schematic of SHPB with a spindle-shaped striker [4].

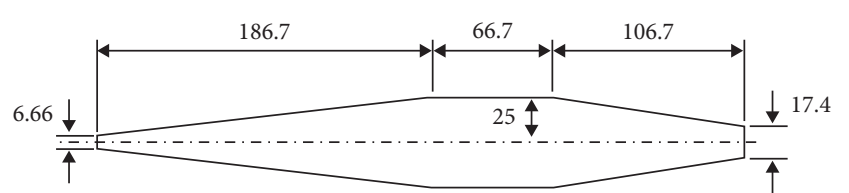

Figure 2: Physical dimensions of a spindle-shaped striker (unit in $\mathrm{mm})$ [15].

pressure bars can be well contacted during testing. Before performing the test, all the specimens were classified into two groups and marked in accordance with the categories of loading waveforms. For instance, specimen R1 is the first sample used in the impact test under the rectangular wave loading. Similarly, the specimen labelled "H2" indicates that this specimen is the second one for the utilization in the halfsine stress wave loading test. Meantime, some mechanical parameters of all the specimens were also measured.

3.2. The Test Results. Prior to carrying out the test, checking that if the SHPB is in a good testing condition is necessary to make sure that the device is operational. Figure 3 gives the attained rectangular and half-sine stress waves after impacting without specimen. In this case to more clearly observe the wave propagation in the SHPB and to make a contrast between the rectangular stress wave and half-sine stress wave over the testing duration, five designed locations on the incident and transmitted bars were given for the measurements of waveforms at different positions. The test results are shown in Figure 4.

From Figures 3(a) and 4(b), it can be found that the oscillation in rectangular waveforms displayed during the measurement period became more and more violent with distance increasing along the bars (from positions I to $\mathrm{V}$ ). The waveform propagating after a short duration fluctuated in larger oscillation amplitude compared with the former waveform, especially for those recorded on the transmitted bar. The biggest oscillation amplitude is nearly half of that of the corresponding waveform, which indicates that when the strain signals measured from gauges $G_{1}$ and $G_{2}$ shown in Figure 1 are used to represent those at both ends of the specimen, the signal distortion occurred. However, observations in the five half-sine pulses (Figure 4(c)) manifested that with increasing distance along the bars, the waveform remained constant and few oscillations can be noted over the entire travelling phase. This suggests that the half-sine stress wave will not disperse when it travels along a bar and that the strain signals gauged by $G_{1}$ and $G_{2}$ under this wave loading can completely replace those at both ends of the specimen for no distortion appeared. The application of a half-sine loading pulse can well overcome the waveform dispersion in the SHPB test, showing that a nondispersive waveform can be obtained, provided the half-sine stress wave was used.

To further illuminate the accuracy of SHPB test results for rock materials, impact tests of red sandstone under rectangular and half-sine stress wave loadings were carried out. The stress equilibrium, strain rate history, and the stress-strain curve oscillation of tested specimens were investigated. Figure 5 shows the typical stress equilibrium of rock specimens under the loadings of rectangular and halfsine stress waves. It can be observed that when the specimen was subjected to the impact with a rectangular loading wave (Figure 5(a)), the computed superposition of incident stress and reflective stress (Inc $+\mathrm{Re}$ ) has a particularly serious fluctuation and greatly differs from the transmitted stress. In other words, a temporary stress equilibrium state was achieved when the time goes by $125 \mu \mathrm{s}$, but it only lasted about $25 \mu \mathrm{s}$. In the condition of half-sine stress wave loading (Figure 5(b)), excellent consistence was found between the Inc + Re stress and transmitted stress, and there is much less fluctuation compared with that under the rectangular wave loading.

The nearly uniform stress and strain rate over most of the loading period is a significant feature of the stressed specimen in the dynamic impact test of rock materials. Figure 6 gives the stress and strain rate histories of representative specimens $\mathrm{R} 4$ and $\mathrm{H} 9$ that were subjected to half-sine and rectangular stress waves, respectively. Comparing the stress and strain rate varying with time of the two specimens finds that the stress of specimen subjected to half-sine stress wave loading remains relatively even over the entire loading duration. Under the rectangular loading wave, the stress fluctuated seriously before the specimen reached the peak stress. Similar observations in the strain rate can also be noted. Most importantly, in the duration of 40 to about $65 \mu$ s (Figure 6(b)), the strain rate resulted from the half-sine stress wave seems to be steady. It means that a half-sine stress pulse enables the rock specimen to deform stably during impact testing. In contrast, at a period of $20 \sim 160 \mu \mathrm{s}$, the strain rate induced by the rectangular stress wave oscillates continuously, showing an unsteady strain of the specimen in most of the loading time.

For the comparison of stress-strain responses of specimens under the action of the two loading waves, six groups of stress-strain curves on 12 specimens were given. Each comprises two specimens with similar average strain rates. As demonstrated in Figure 7, the resultant stress-strain curves of specimens induced by rectangular wave loading show great volatility before the peak stress of a rock specimen is reached. More exactly, there are almost four wave fluctuations before the specimen was brought to peak stress in the resultant stress-strain curve. The biggest stress oscillation amplitude among the four fluctuations on every stress-strain relation has 


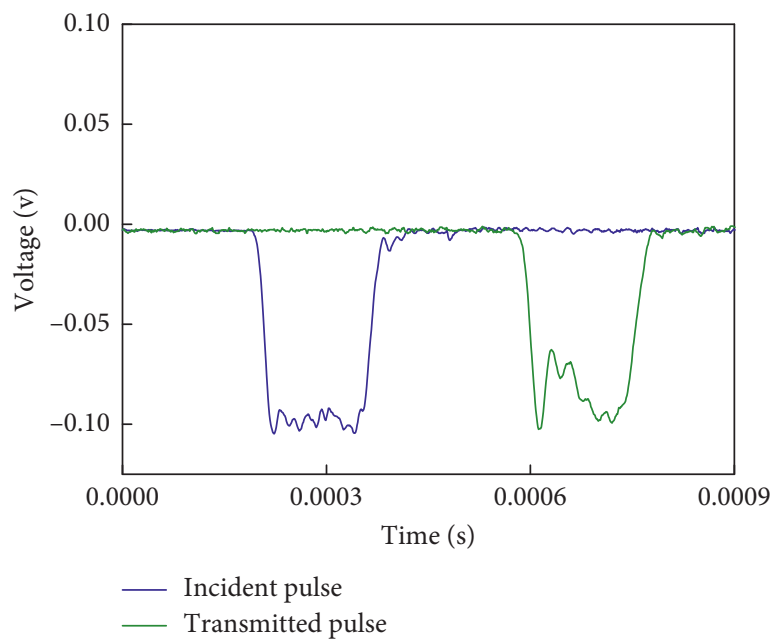

(a)

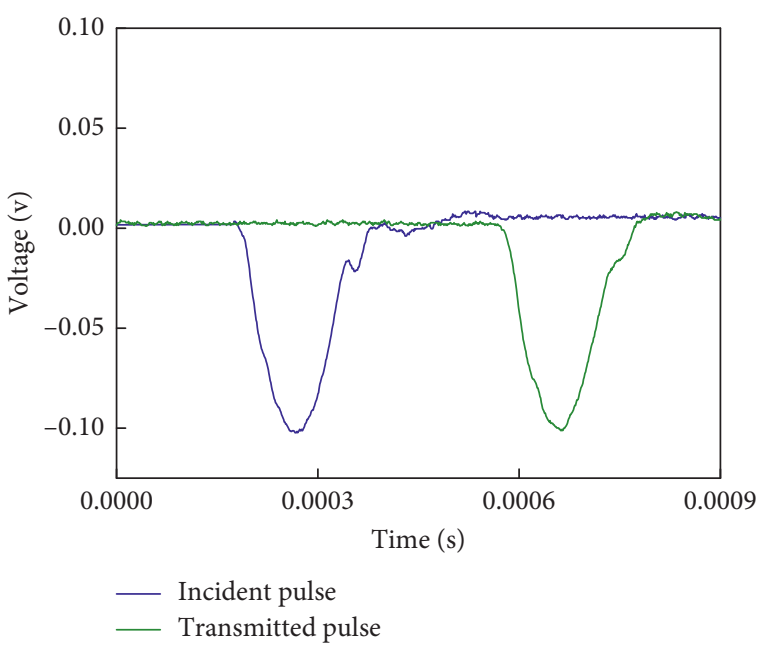

(b)

FIGURE 3: (a) Rectangular stress waveform and (b) half-sine stress waveform when impacting without specimen.

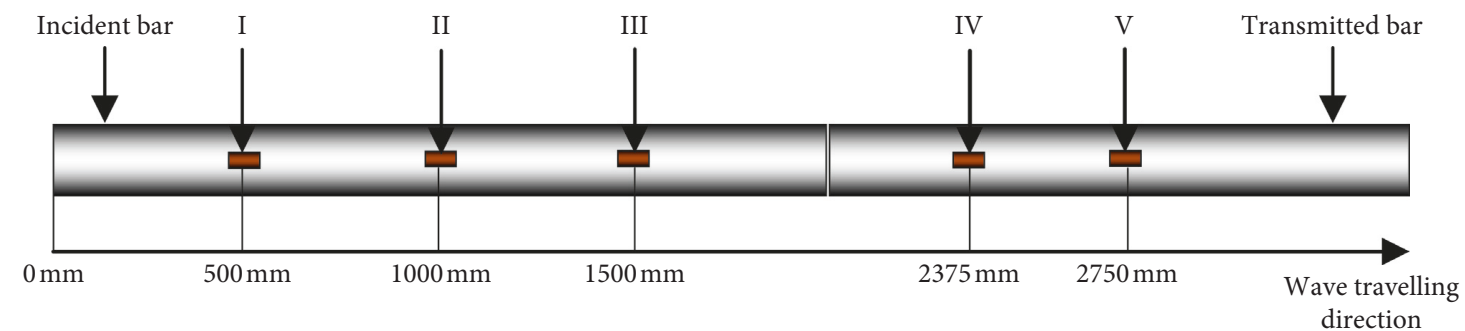

(a)

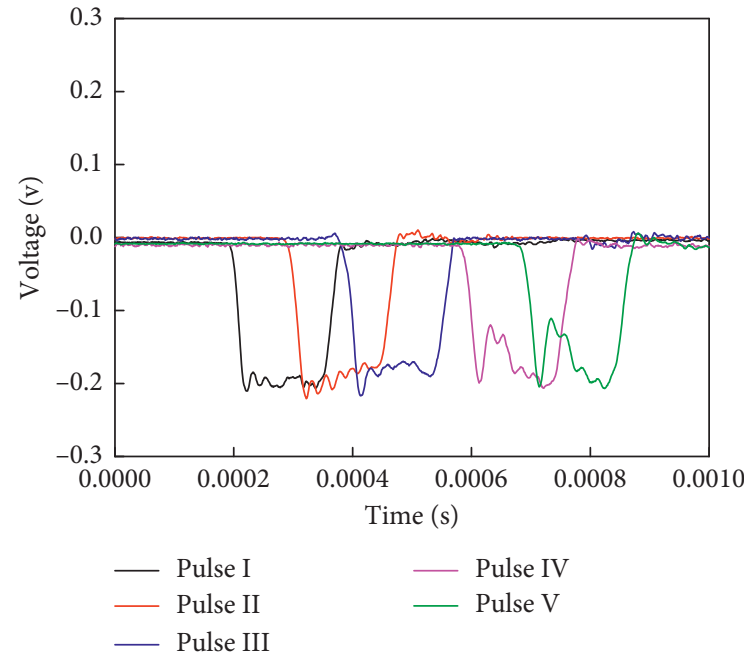

(b)

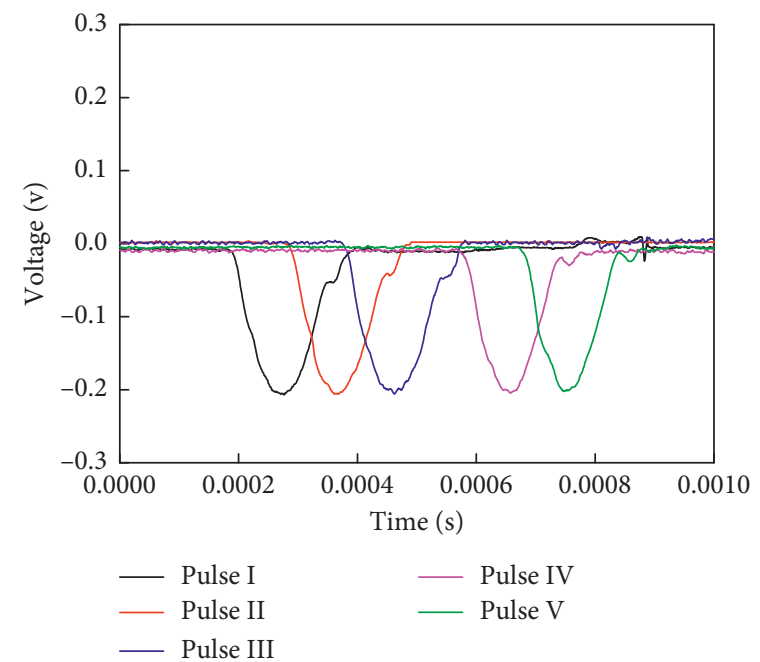

(c)

FigURE 4: Representation of gauge stations and recorded waveforms at different given locations in the 50 mm diameter SHPB.

reached $1 / 3$ to $1 / 2$ of the peak stress of the corresponding specimen. The fractures of loaded specimens are displayed in Figure 8 , wherein it can be seen that, with similar strain rates, the damage degrees of the rock specimens under the two stress waveform loadings are quite close. The tested sandstone in this paper belongs to the argillaceous siltstone. It also can be seen from Figure 8 that, although the lubricant is applied at both ends of the specimen during testing, a certain friction effect still exits, which results in the conical rupture surface on the specimen fragments.

Conversely, the stress-strain curve of the specimen loaded by the half-sine stress wave behaves well and 


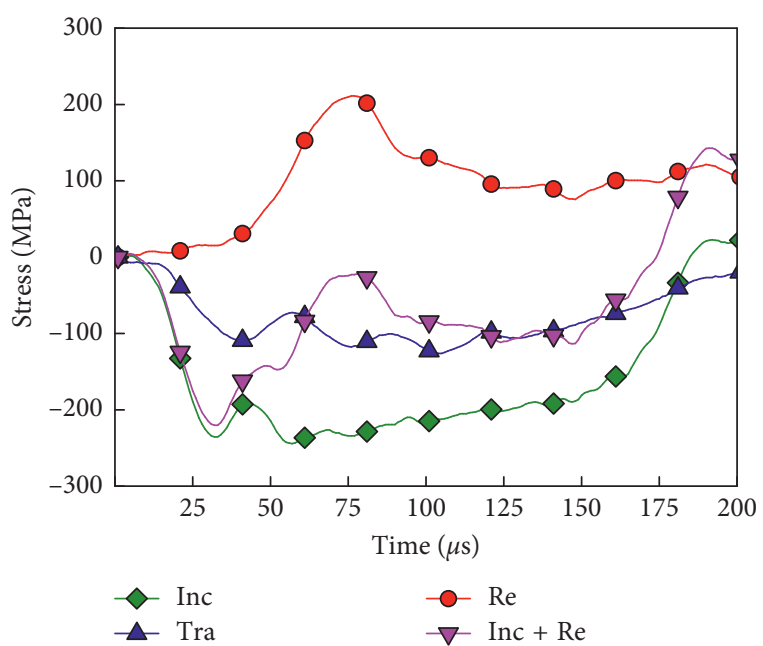

(a)

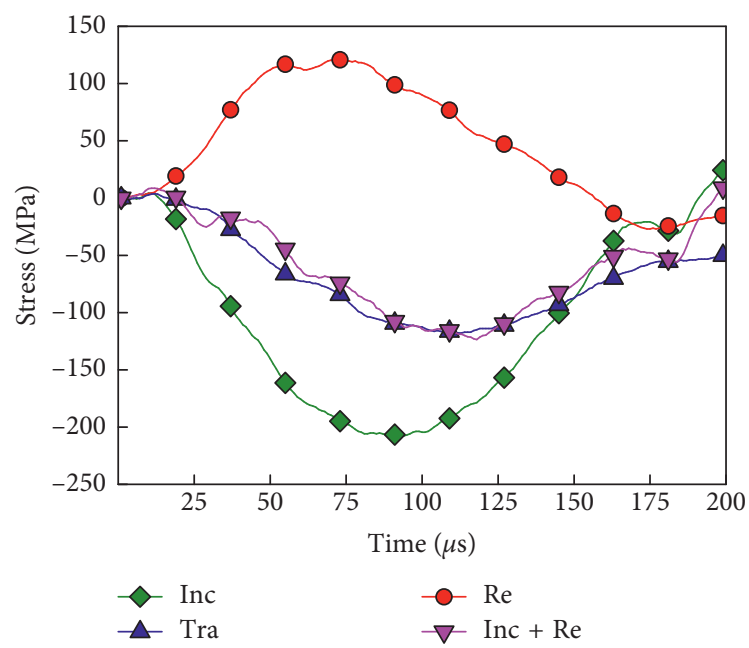

(b)

FIgURE 5: Typical dynamic stress equilibrium of rock specimens under (a) rectangular wave loading and (b) half-sine stress wave loading.

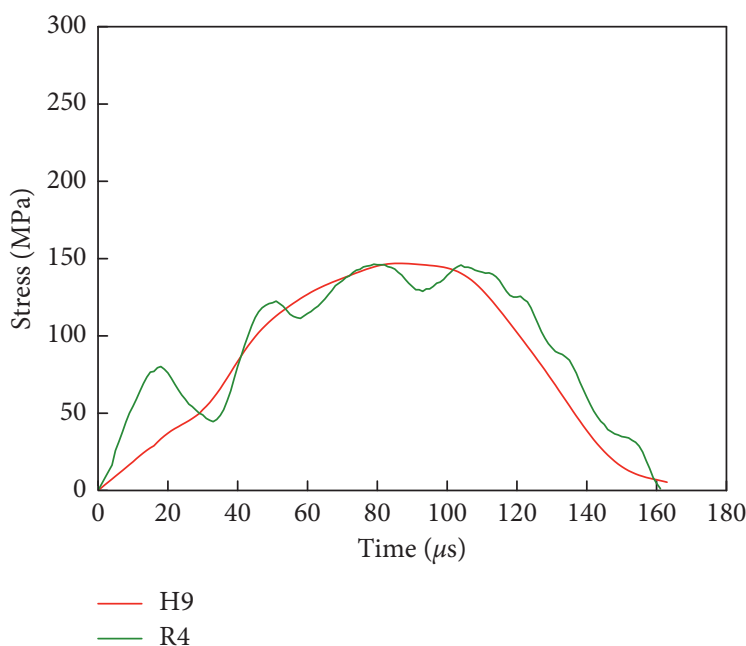

(a)

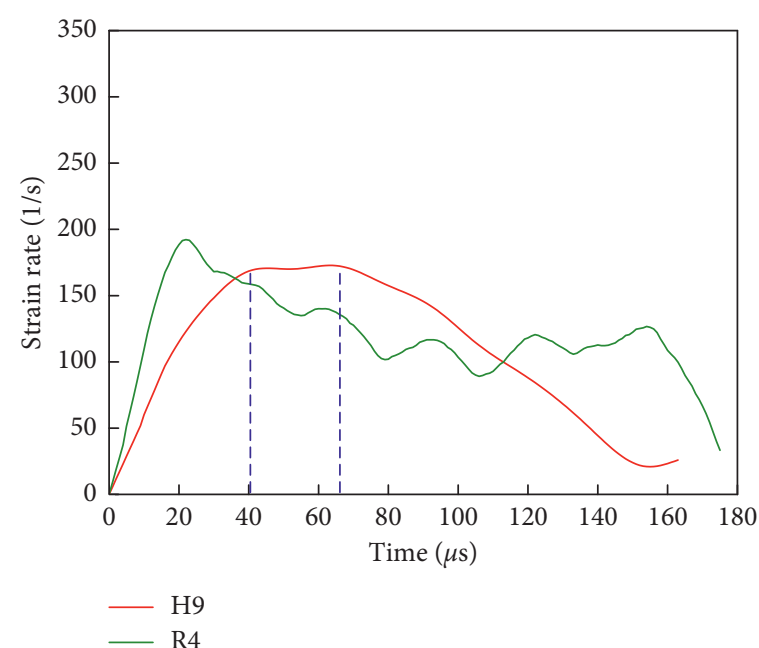

(b)

FIgURE 6: Stress (a) and strain rate (b) histories of specimens H9 and R4.

possesses little fluctuation. The half-sine stress loading wave produced a smother stress-strain relationship. To make a further comparison, the data of peak stress and energy absorption per unit of tested specimen were plotted as functions of the strain rate, as given by Figure 9 .

It can be known that the energy absorption per unit resulted from both loading waves increases with the strain rate. At a similar strain rate, the specimen under rectangular pulse absorbed more energy compared with that under the half-sine stress pulse. And there appears to be no obvious difference in the degrees of data dispersion. However, the data of peak stress derived from the rectangular loading pulse are relatively scattered than those from the half-sine stress wave, for the phenomenon that the data area of half-sine stress wave is within the area range of the rectangular loading wave.

The accuracy of experimental results is closely related to the transmission process of the stress wave in the rock SHPB test. In order to further illustrate the rationality of the halfsine stress wave loading, the following paper numerically simulated the propagation process of the rectangular, triangular, and half-sine stress waves and investigated the influences of the bar diameter size and propagation distance on the waveform dispersion.

\section{Numerical Simulation}

4.1. The Three-Dimensional Numerical Model. Combined with the afore experimental approach, three typical stress waveforms, the rectangular, triangular, and half-sine stress waves, were selected as the loading waves to investigate the wave propagations in the SHPB by the numerical method. In [18], the propagation of the three stress waves in a $75 \mathrm{~mm}$ diameter elastic bar was simulated. However, the size effect of bar diameter on the propagation of stress waves was not 


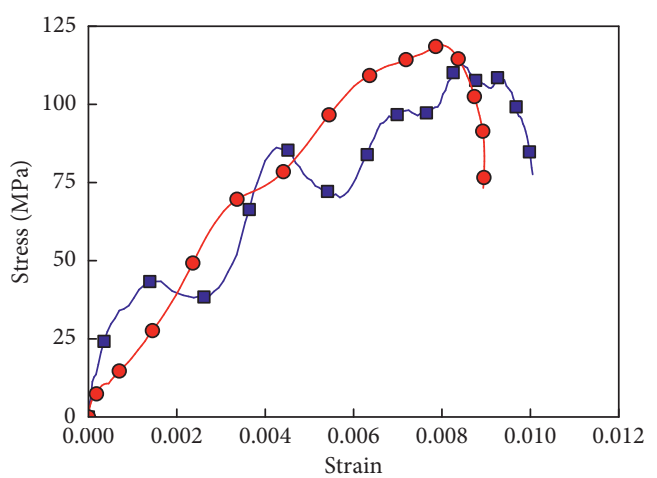

$\rightarrow$ R7

Peak stress $=112.56 \mathrm{MPa}$

Strain rate $=80.701 / \mathrm{s}$

- $\mathrm{H} 1$

Peak stress $=118.92 \mathrm{MPa}$

Strain rate $=77.41 \mathrm{l} / \mathrm{s}$

(a)

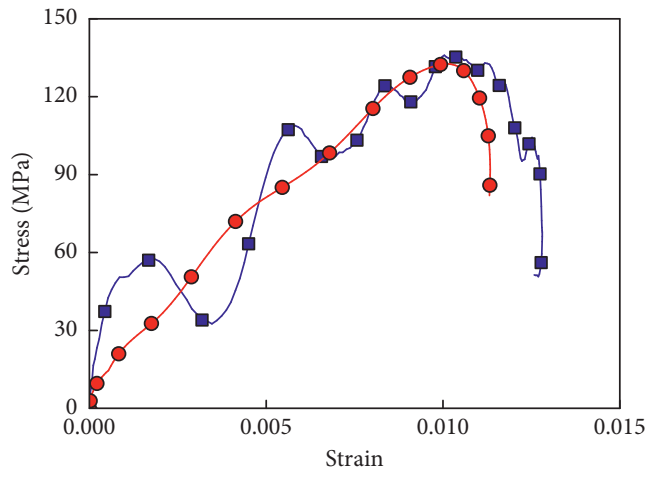

$\rightarrow-\mathrm{R} 1$

Peak stress $=135.95 \mathrm{MPa}$

Strain rate $=95.601 / \mathrm{s}$

$-\mathrm{O}$ H3

Peak stress $=132.63 \mathrm{MPa}$

Strain rate $=97.591 / \mathrm{s}$

(c)

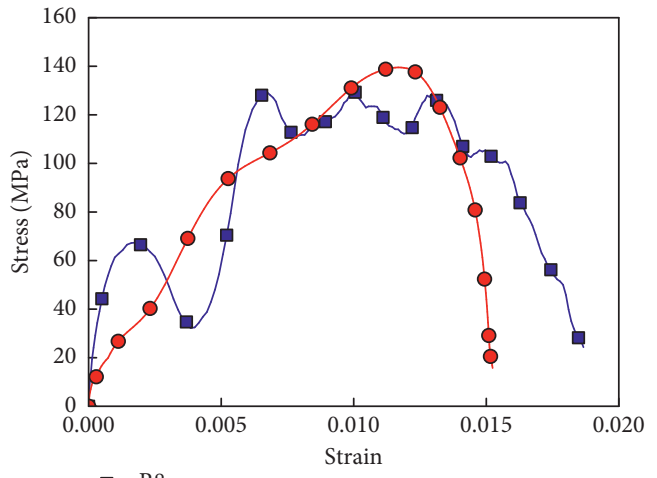

R8

Peak stress $=129.51 \mathrm{MPa}$

Strain rate $=124.421 / \mathrm{s}$

- $\mathrm{H} 7$

Peak stress $=139.5 \mathrm{MPa}$

Strain rate $=122.911 / \mathrm{s}$

(e)

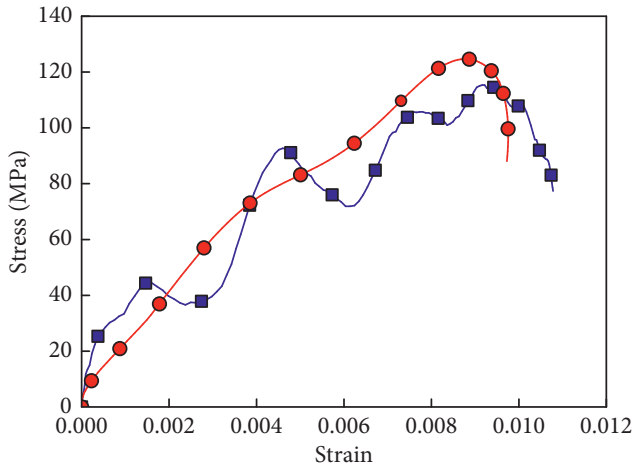

- R6

Peak stress $=115.34 \mathrm{MPa}$

Strain rate $=86.411 / \mathrm{s}$

$-\mathrm{O}-\mathrm{H} 2$

Peak stress $=124.65 \mathrm{MPa}$

Strain rate $=89.831 / \mathrm{s}$

(b)

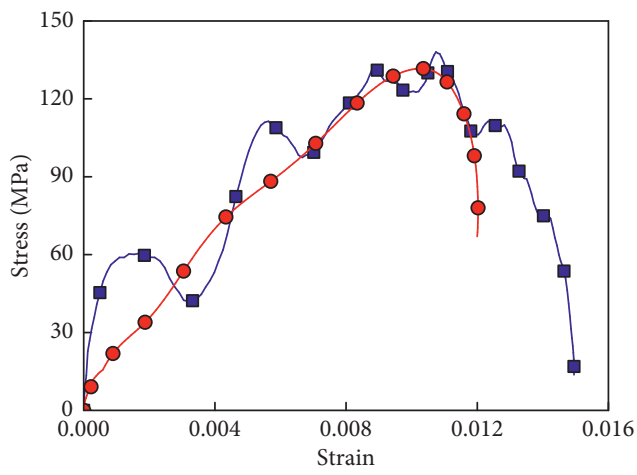

- R11

Peak stress $=138.05 \mathrm{MPa}$

Strain rate $=102.301 / \mathrm{s}$

Peak stress $=131.69 \mathrm{MPa}$

Strain rate $=102.761 / \mathrm{s}$

(d)

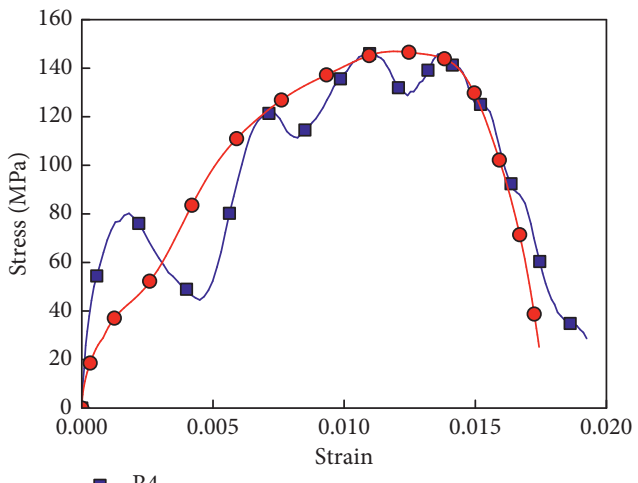

Peak stress $=146.34 \mathrm{MPa}$

Strain rate $=135.911 / \mathrm{s}$

-o- H9

Peak stress $=146.92 \mathrm{MPa}$

Strain rate $=136.551 / \mathrm{s}$

(f)

FiguRE 7: Stress-strain relationships of specimens at similar strain rate under the loadings of rectangular and half-sine waves. 

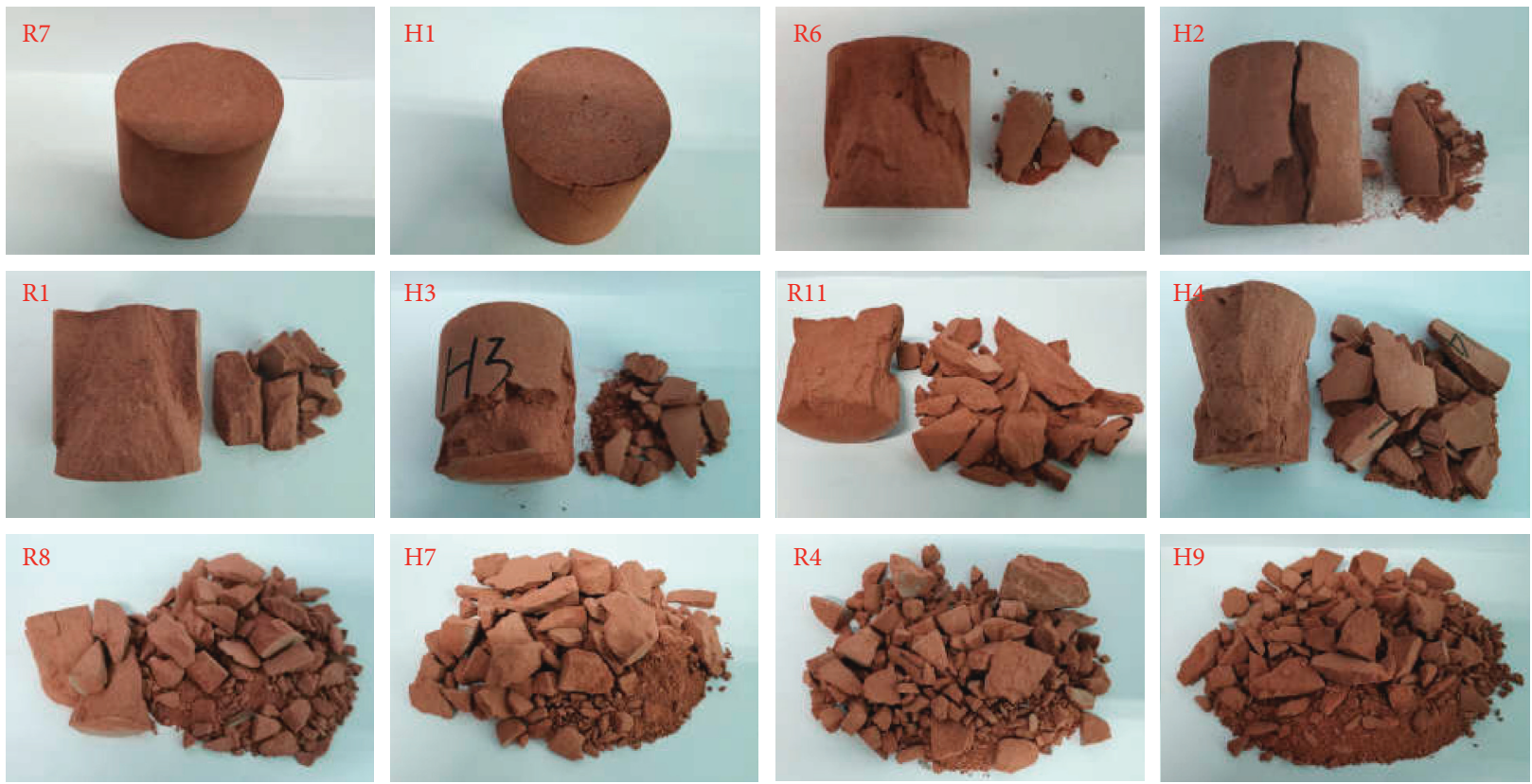

FIGURE 8: Fragments of tested specimens.

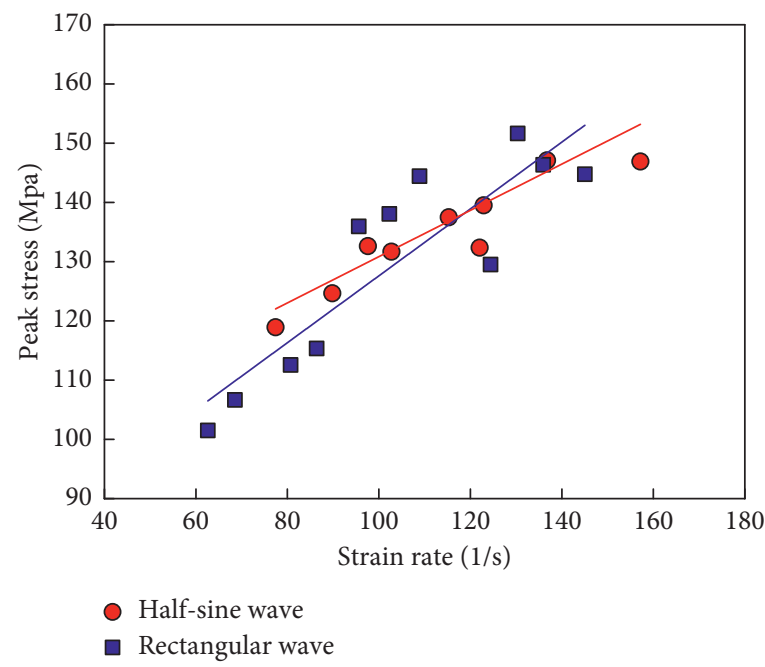

(a)

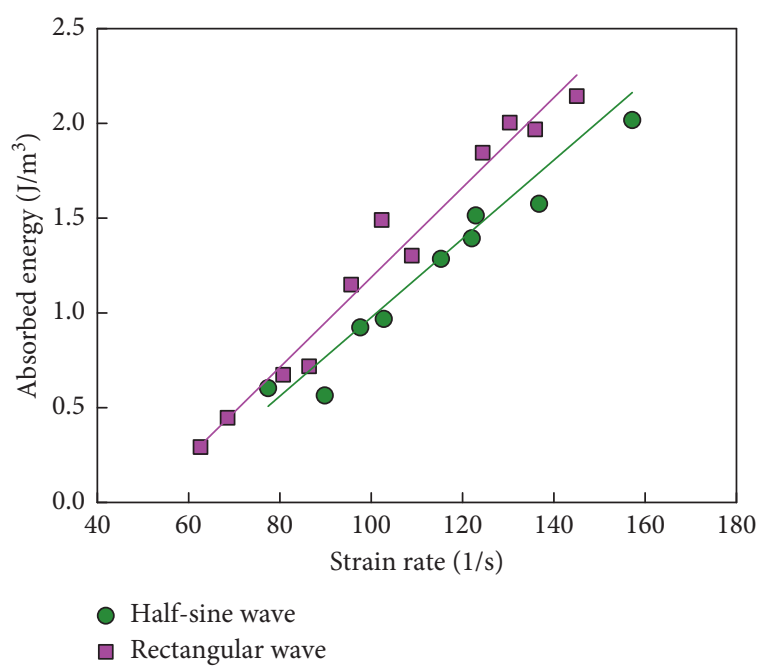

(b)

FIGURE 9: Relationships of the peak stress, energy absorption, and strain rate of fragmented specimens.

investigated. A three-dimensional model (Figure 10) of the incident bar with the same length $2000 \mathrm{~mm}$ and four diameter sizes was established using ANSYS/LS-DYNA [19]. The density, elastic modulus, and Poisson ratio of the incident bar are $7795 \mathrm{~kg} / \mathrm{m}^{3}, 250 \mathrm{GPa}$, and 0.285 , respectively.

In this model, the three stress waves were separately applied to elastic incident bars that are in four diameter sizes $(10,22,38$, and $50 \mathrm{~mm})$, to study the dispersion effect of bar diameter on the one-dimensional stress wave propagation. The durations of the selected loading waveforms were consistently set with their peak stresses. That is, the duration and the peak stress of waveforms were set as $200 \mu$ s and $200 \mathrm{MPa}$, respectively. Assuming that the stress waveform on the surface is replaceable to that on the bar cross-section, the recording positions were located along the longitudinal orientation of the elastic bar. The distances from the loaded end of the bar to gauge stations are $0,250,500,750$, and $1000 \mathrm{~mm}$.

4.2. The Waveform Oscillation. In this section, the three above-mentioned stress waveforms propagating in two elastic bars with diameters of 10 and $50 \mathrm{~mm}$ were chosen to analyze their oscillation phenomena. The rectangular stress waves collected at different positions in the 10 and $50 \mathrm{~mm}$ diameter elastic bars are illustrated in Figure 11. For stress 


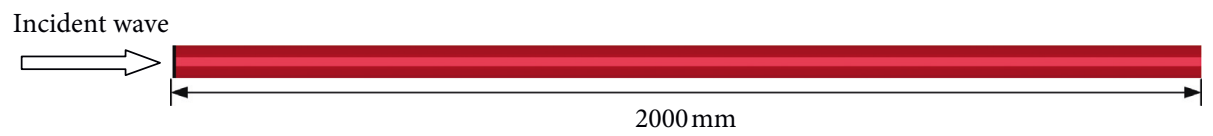

FIGURE 10: ANSYS model of incident bar and schematic diagram of impact loading.

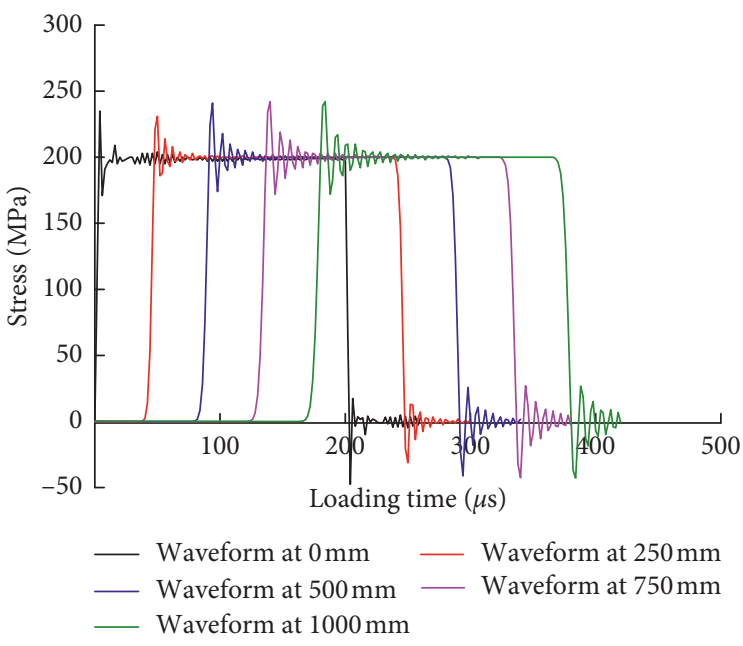

(a)

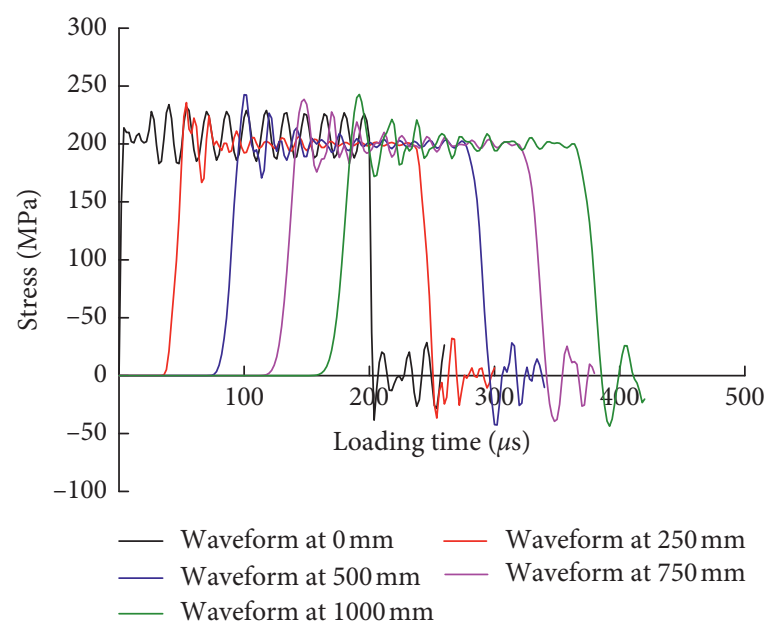

(b)

FIGURE 11: Rectangular waveforms at different propagation distances in (a) 10 [19] and (b) 50 mm diameter bars.

waves in the $10 \mathrm{~mm}$ diameter bar, it can be seen that the waveform becomes more oscillatory with increasing propagation distance. Clearly, when the stress wave lasts to half of the duration, it returns to the original waveform, and a platform is formed (Figure 11(a)). Compared with the waveforms in the $\Phi 10 \mathrm{~mm}$ bar, the wave oscillation in the $50 \mathrm{~mm}$ diameter bar is more serious, and the peak value of stress wave has no clearly monotone changes with the propagation distance (Figure 11(b)). Throughout the duration, the propagated waveform basically no longer returns to the original one and has been greatly changed. Thus, in this case, the stress waves recorded on the bar surface cannot delegate the actual waves, owing to their significant differences following propagations.

Figure 12 represents the triangular stress waves propagating in the two early mentioned elastic bars. It indicates that the triangular waveforms in the two bars can maintain a triangular shape during their travelling process, and the waveform oscillation is very less. However, it is obvious that the peak value of the waveform gradually decreases with the increase in propagation distance. Moreover, the decreasing trend of the wave peak value in the $\Phi 50 \mathrm{~mm}$ bar is more visible than that in the $\Phi 10 \mathrm{~mm}$ bar (see the dotted arrows in Figure 12). By comparing the waveforms in Figures 12(a) and 12(b), it can be inferred that the theory of onedimensional stress wave can be satisfied during the wave propagation process in a small diameter bar of the SHPB, as the waveform oscillation is not too serious to make an analysis and the errors are ignorable. But as the bar diameter increases, the waveform oscillation will be more serious, which would cause the one-dimensional stress wave hypothesis to be unsatisfied.
Similarly, the half-sine stress waveform was also selected to make a comparison, as demonstrated in Figure 13. It can be found that whether propagating in the $\Phi 10$ or $\Phi 50 \mathrm{~mm}$ bars, the waveform is not affected by propagation distance and there is almost no waveform oscillation. As marked in the figure by arrows, the original peak value of the half-sine wave remains unchanged as the loading time increases. After the comparison of stress waveforms at a same propagation distance in the two bars, it is observed that the waveforms are basically remained identical and the changes are very small, concluding that the propagation of the half-sine wave almost does not be influenced by bar diameter.

4.3. The Peak Attenuation of Stress Wave. The wave propagation from the aspect of oscillation degree has been qualitatively analyzed in the above section, whereas it has not been compared quantitatively. Thereafter, the peak stress $\sigma_{\text {max }}$ and rising time $t_{\mathrm{r}}$ of stress wave were employed to make a quantitative comparison. Additionally, the concepts of the peak factor $\sigma_{\max }^{*}$ and rising time factor $t_{\mathrm{r}}^{*}$ for stress wave were given, where $\sigma_{\max }^{*}$ is defined as the ratio of the peak value of stress wave after running a certain distance to that of the original waveform and $t_{\mathrm{r}}^{*}$ is the ratio of rising time of a propagated stress wave to that of the initial waveform. Utilizing the two factors, not only the comparison can be quantificationally made but also the deviation size between the transmitted waveform and original waveform can be easily obtained [19].

For the rectangular stress wave, the variation of the peak factor with propagation distance in different diametrical bars was investigated, as manifested by Figure 14. The general 


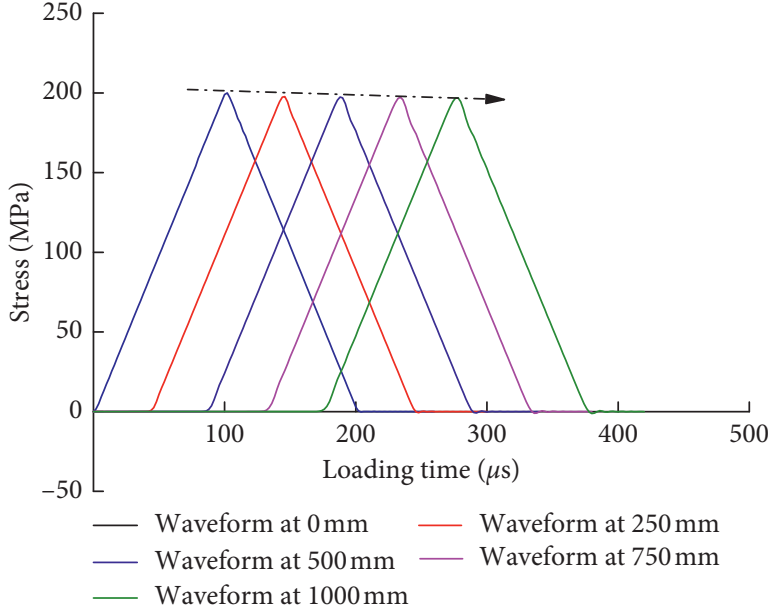

(a)

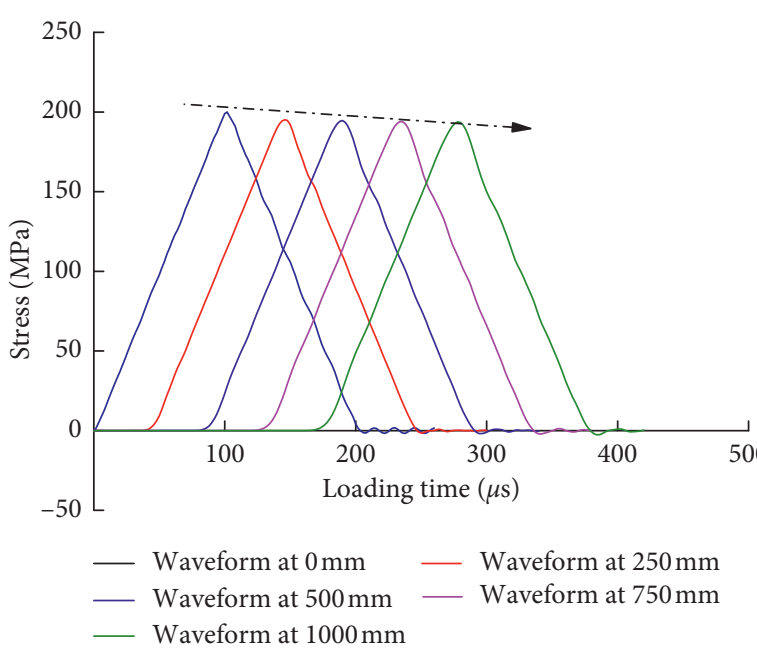

(b)

Figure 12: Triangular waveforms at different propagation distances in (a) 10 [19] and (b) $50 \mathrm{~mm}$ diameter bars.

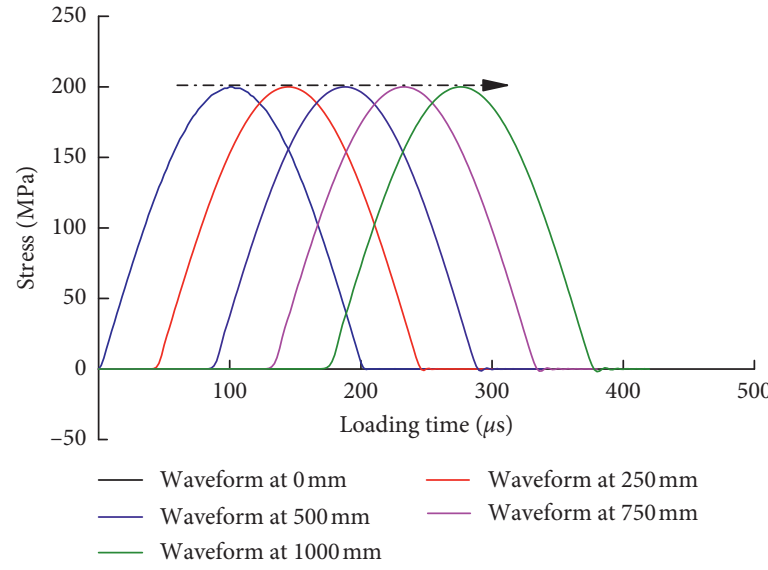

(a)

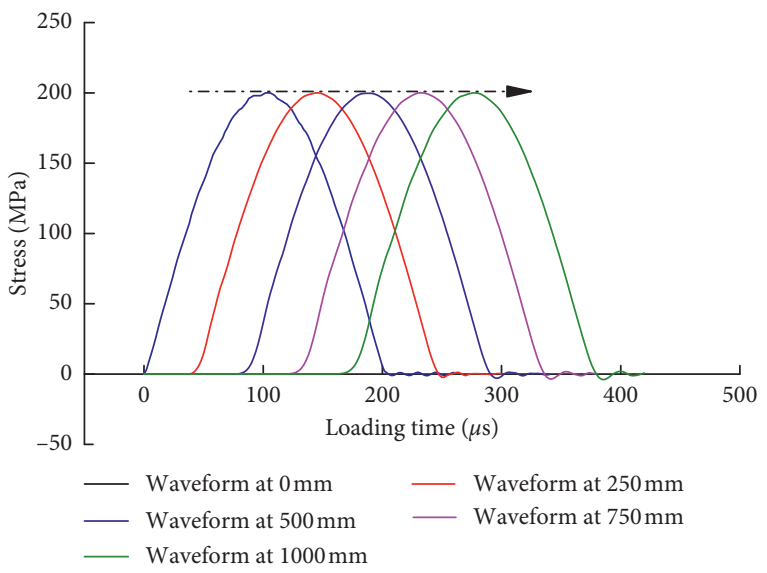

(b)

Figure 13: Half-sine waveforms at different propagation distances in (a) 10 [19] and (b) $50 \mathrm{~mm}$ diameter bars.

trend displayed can be considered that, as the propagation distance increases, the increasing trend of the peak factor tends to be stable. Among these peak factors, the minimum value is 1.10 and the maximum value is up to 1.30 . That is, the maximum increment in the peak factor is $10 \%$ and the maximum increment reaches $30 \%$. When the stress wave travels from the loading end to a propagation distance of $250 \mathrm{~mm}$, the peak factor of the stress wave is greatly affected by the bar diameter, while it begins to fluctuate at about 1.20 after exceeding $250 \mathrm{~mm}$ in propagation distance (Figure 14(b)). This indicates that, after a long-distance propagation, the peak factor of the rectangular stress wave is about to be steady, and the increase in the peak stress is maintained at approximately $20 \%$.

The travelling of the triangular stress wave in different diametral bars was also investigated in terms of the peak factor, as depicted by Figure 15. It can be seen that for all diameters, the peak factor of triangular gradually decreases with the increase in propagation distance, and there is no oscillation fluctuation phenomenon. For wave propagation in the $10 \mathrm{~mm}$ elastic bar, after a distance of $1000 \mathrm{~mm}$, the peak factor decreased to 0.98 , namely, the peak value was only reduced by appropriately $2 \%$. When the propagation distance is small, the peak factor of the triangular stress wave decreases with the increase of bar diameter. The decreasing tendency becomes more obvious as the propagation distance increases.

Figure 16 plots the changes in the peak factor of the halfsine stress wave with propagation distance. For all bar diameters, the peak factor of the half-sine stress wave does not substantially change with propagation distance and nearly not be affected by the bar diameters at the same propagation distance. The peak factor of the half-sine stress wave is maintained around 1.00. Relative to the rectangular and triangular stress waves, it can be considered that the peak factor of the half-sine stress wave is negligibly affected by the propagation distance as well as bar diameter. 


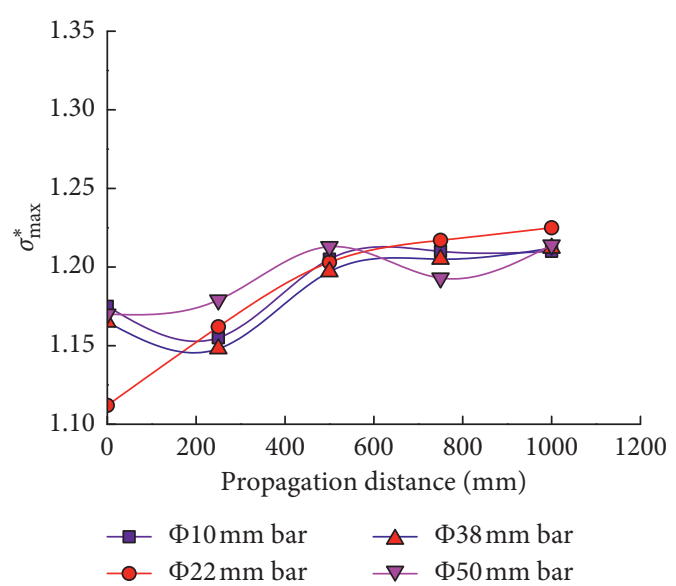

(a)

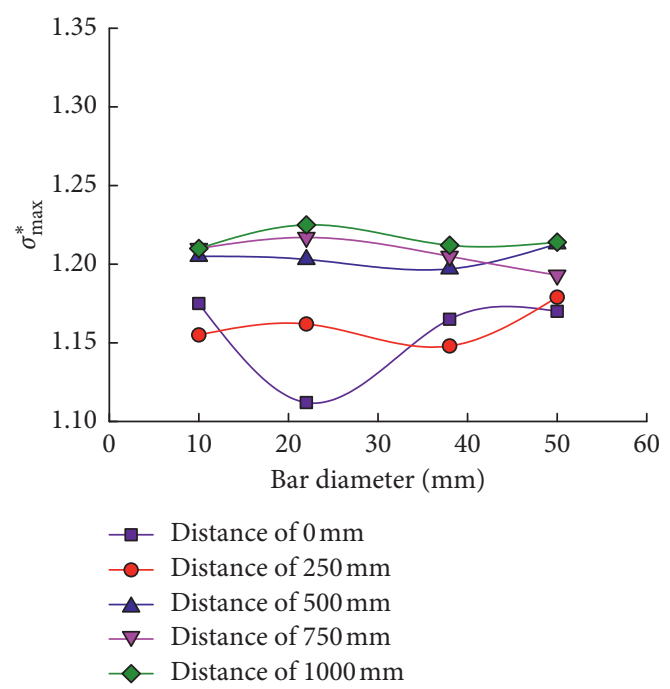

(b)

FIGURE 14: Variations of the peak factor of rectangular wave with (a) propagation distance and (b) bar diameter.

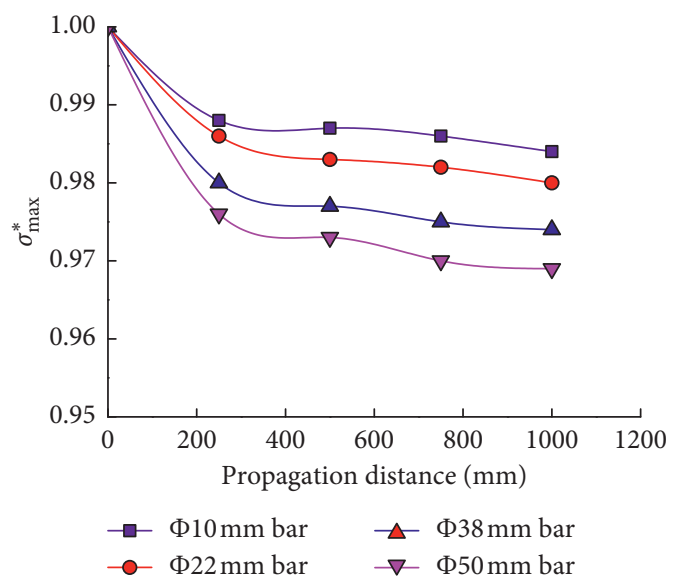

(a)

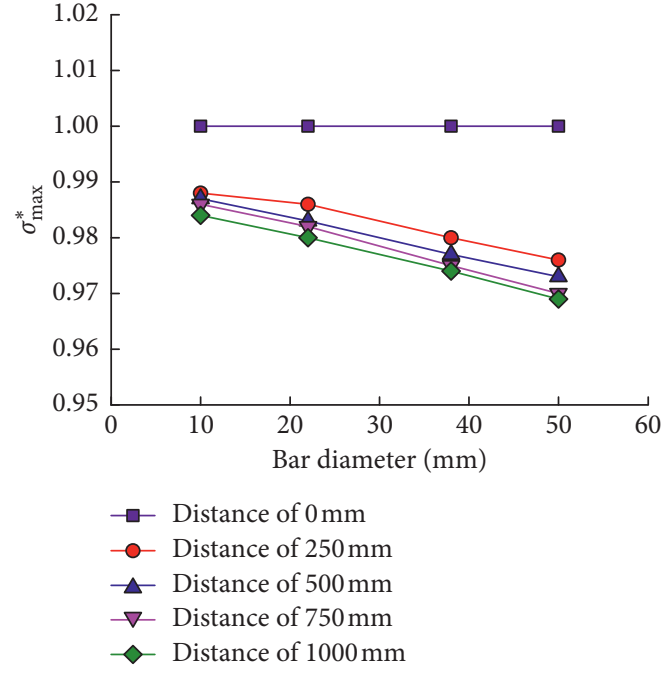

(b)

FIGURE 15: Variation of the peak factor of triangular wave with (a) propagation distance and (b) bar diameter.

4.4. The Increasing Trend in Rising Time of Waveform. Curves in Figure 17 suggest that, at the ends of all diametrical incident bars, the rising time of the rectangular wave is in a range of $4 \sim 8 \mu \mathrm{s}$. With the propagation of the rectangular wave, the rising time in each bar diameter goes up. At the distance of $1000 \mathrm{~mm}$, the rising time in the $\Phi 10 \mathrm{~mm}$ bar is $16 \mu \mathrm{s}$ and that in the $50 \mathrm{~mm}$ diameter bar is about $30 \mu \mathrm{s}$. Such a short rising time is not suitable for the impact tests of rocks. In addition, in the case of similar propagation distances in different bars, the rising time increases with bar diameter, which indicates that the bar diameter has a great influence on the rising time of the rectangular waveform.

The rising time factor of the triangular wave varying over the propagation distance and bar diameter was also analyzed, as displayed by Figure 18. The rising time factor increases with increasing propagation distance for each bar. But among these changes, its maximum increment is only $4 \%$. For a small diameter elastic bar, the increase in the rising time factor is less than that in the large diameter bar with the propagation of the triangular wave, which can be basically considered as that no changes in rising time will occur. Furthermore, after a short propagation distance, the rising time factor for each bar can be considered as not changing (Figure 18(b)). Only with the increase in propagation distance, the rising time will increase, and their differences gradually become more evident.

The rising time factor of the half-sine stress wave has been analyzed from two influential elements: the propagation distance and bar diameter shown in Figure 19. 


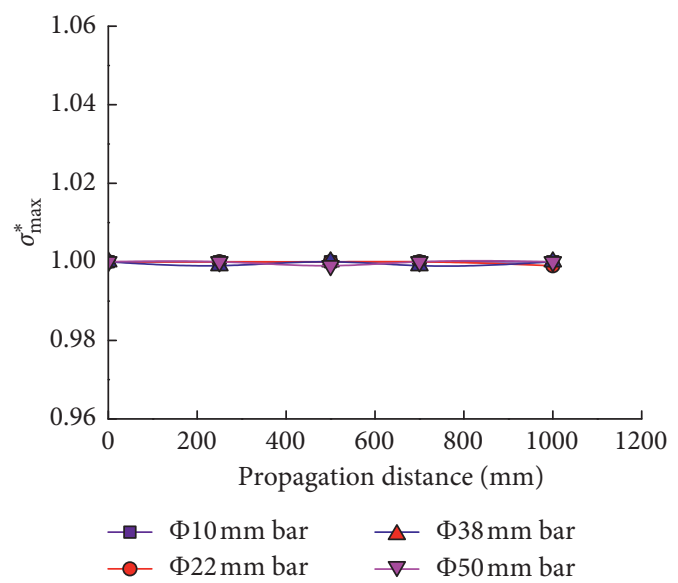

FIGURE 16: The variation of the peak factor of half-sine wave with propagation distance in bars with different diameters.

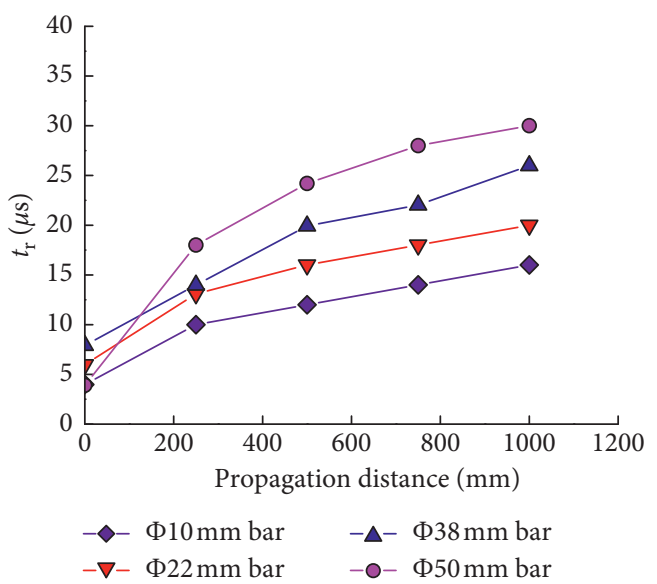

(a)

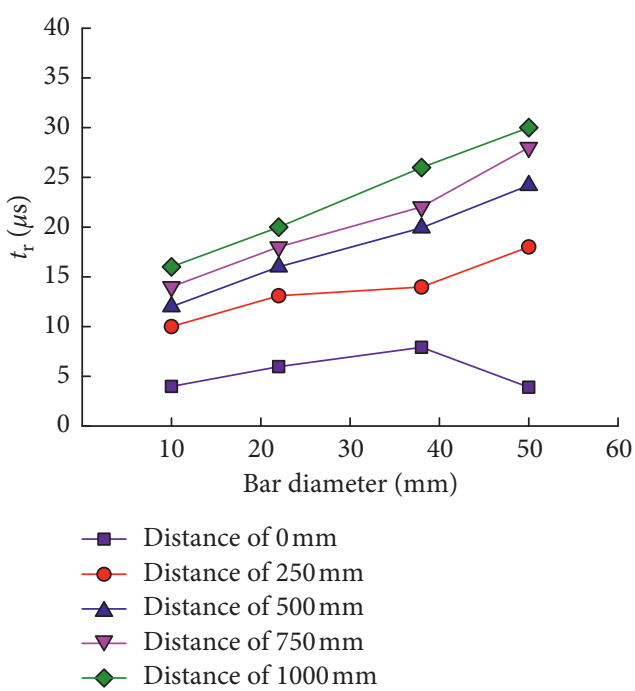

(b)

FIGURE 17: The variation of the rising time of rectangular wave versus (a) propagation distance and (b) bar diameter.

Compared with the changes of the triangular wave, the increment of the rising time factor of the half-sine stress wave is less than that of the triangular wave. For the half-sine stress wave, the rising time factor will slowly increase with increasing propagation distance, while the maximum increase is only $2 \%$, which only occurs in bars with their diameters greater than $38 \mathrm{~mm}$. For the bar with a smaller diameter $(\Phi<38 \mathrm{~mm})$, the rising time of the half-sine stress wave is not affected by the propagation distance.

\section{Discussion}

Since the elastic wave can be regarded as the combination that is superimposed by harmonic components with different frequencies, the different components will travel forward according to their respective phase velocities and the original stress waveform will gradually disperse during the propagation process, representing the dispersion in a spreading waveform.

The waveform dispersion mainly includes the following four aspects: (i) stress waveform oscillates during propagation. The phase velocity of each harmonic depends on the ratio of bar diameter to wavelength. In the condition of increasing bar diameter or decreasing wavelength, the waveform oscillation becomes more serious as the propagation distance increases [20]; (ii) due to the transverse inertia effect, the rising trend of stress wave will become more relaxed as the propagation distance increases, resulting in gradual increase in rising time; (iii) the peak value of the stress wave will decrease with increasing propagation distance because of the transverse inertia effect. Accordingly, the waveform will be very different from the original one after a long propagation distance; (iv) the wave propagation in the SHPB test is premised on the assumption that stresses 


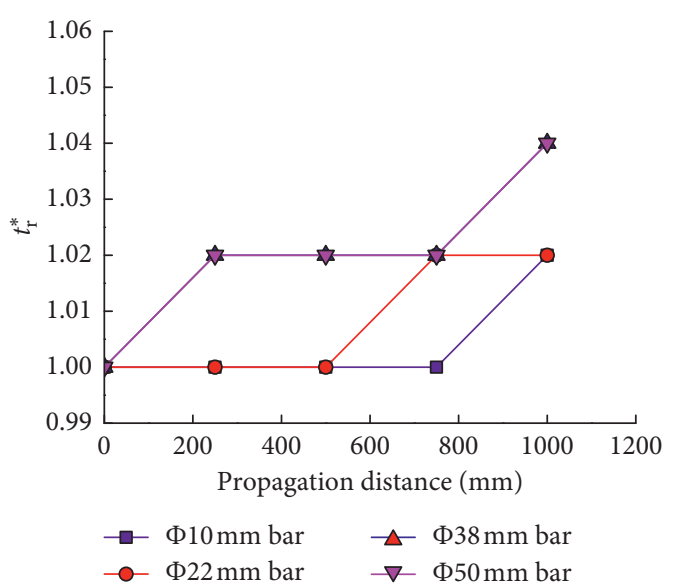

(a)

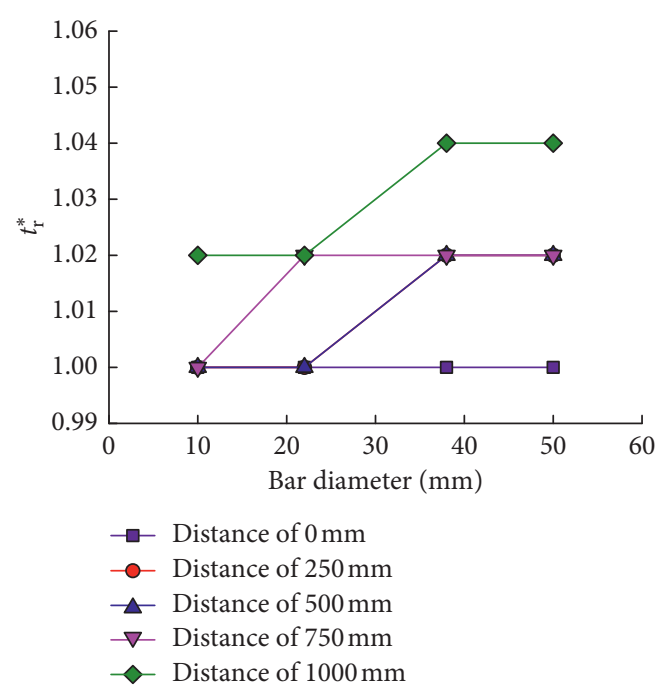

(b)

FIGURE 18: The change of the rising time factor of the triangular wave versus (a) propagation distance and (b) bar diameter.

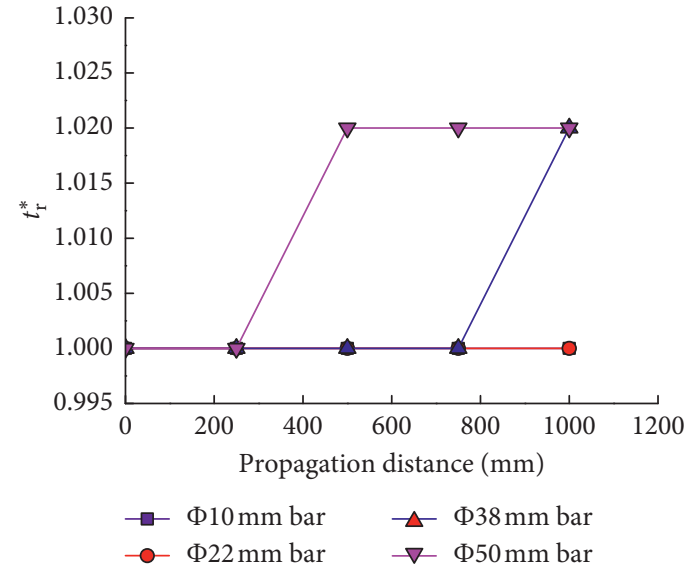

(a)

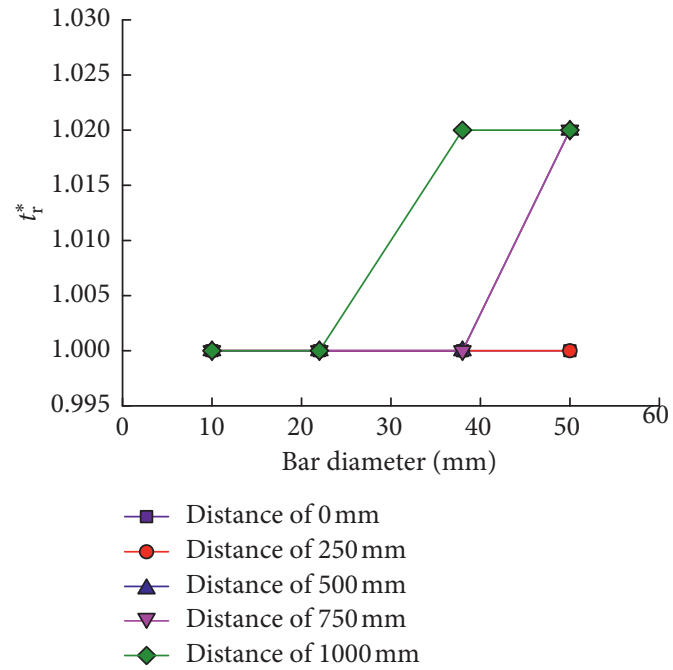

(b)

Figure 19: The change in rising time factor of half-sine wave versus (a) propagation distance and (b) bar diameter.

in the cross-section of the elastic bar are evenly distributed and the one-dimensional stress wave propagation is satisfied. However, the transverse inertial effect will cause stresses to unevenly distribute on elastic bar cross-section.

Wave dispersion actually occurs in both longitudinal (along the axial direction of bar) and transverse directions (along the radial direction of cross-sectional area). But, because the waveform dispersion in the longitudinal direction is more intuitive and easy to measure, most of previous researches have focused on how to eliminate the longitudinal waveform dispersion. Few attentions were paid on the elimination of transverse waveform dispersion because of limited analytical approaches. Therefore, the numerical simulation is a feasible technique of analyzing waveform dispersion. Meanwhile, it is a viable method to use the three-dimensional numerical model to simulate and analyze the ideal waveform without dispersion in rock impact test using the large diameter SHPB device.

\section{Conclusions}

To systematically investigate the rational loading waveform in SHPB rock tests with large diameter, the laboratory tests and numerical simulations were carried out in this paper. The main conclusions are as follows:

(1) Dynamics tests of red sandstone under rectangular and half-sine stress waves were conducted by using an $\varnothing 50 \mathrm{~mm}$ SHPB apparatus. In the case of rectangular wave loading, the signal obtained by the 
SHPB test system is already distorted from the actual force acting on rock specimen due to unavoidable waveform dispersion, making the experimental results inaccurate. However, the waveform dispersion will not occur in the travelling process of the halfsine stress wave, and the test signal can well represent the actual force at the ends of the specimen. The obtained results are relatively accurate.

(2) The comparative test with red sandstone performed in this research shows that the half-sine stress wave has good superiority in ensuring the stress equilibrium at both the ends of the specimen and stressstrain curve smoothness. The obtained results can truly interpret the dynamic mechanical responses of tested rock materials.

(3) For the rectangular, triangular, and half-sine loading waves, the influences of bar diameter size and propagation distance on the wave dispersion are investigated by numerical simulation. The results show that compared with the other two loading waves, the half-sine stress wave is little effected by the bar diameter and propagation distance during the SHPB test, which is the reasonable loading waveform in the SHPB test for rock materials.

\section{Data Availability}

The data used to support the findings of this study are available from the corresponding author upon request.

\section{Conflicts of Interest}

The authors declare that they have no conflicts of interest.

\section{Acknowledgments}

This paper was financially supported by the National Natural Science Foundation of China (grant no. 41472269), the Research Project of State Key Laboratory of Coal Resources and Safe Mining, CUMT (13KF06), and the Fundamental Research Funds for the Central Universities of Central South University (2018zzts735).

\section{References}

[1] Q. Zhang and J. Zhao, "A review of dynamic experimental techniques and mechanical behaviour of rock materials," Rock Mechanics and Rock Engineering, vol. 47, no. 4, pp. 1411-1478, 2014.

[2] L. Chen, Q. Fang, X. Jiang, Z. Ruan, and J. Hong, "Combined effects of high temperature and high strain rate on normal weight concrete," International Journal of Impact Engineering, vol. 86, pp. 40-56, 2015.

[3] C. Zhai, L. Chen, Q. Fang, W. Chen, and X. Jiang, "Experimental study of strain rate effects on normal weight concrete after exposure to elevated temperature," Materials and Structures, vol. 50, no. 1, pp. 1-40, 2017.

[4] F. Q. Gong and G. F. Zhao, "Dynamic indirect strength of sandstone under different loading rates," Rock Mechanics and Rock Engineering, vol. 47, no. 6, pp. 2271-2278, 2014.
[5] Sharpe Jr. and N. William, Springer Handbook of Experimental Solid Mechanics, Springer-Verlag, Berlin, Germany, 2008.

[6] ISRM Testing Commission, "Suggested method for determining tensile strength of rock materials," International Journal of Rock Mechanics and Mining Sciences and Geomechanics Abstracts, vol. 15, no. 6, pp. 99-103, 1978.

[7] X. B. Li, T. S. Lok, and J. Zhao, "Dynamic characteristics of granite subjected to intermediate loading rate," Rock Mechanics and Rock Engineering, vol. 38, no. 1, pp. 21-39, 2005.

[8] Q. Fang, J. Hong, J. H. Zhang, C. Li, and Z. Ruan, "Issues of SHPB test on concrete-like material," Engineering Mechanics, vol. 31, pp. 1-14, 2014.

[9] W. F. Heard, B. E. Martin, X. Nie, T. Slawson, and P. K. Basu, "Annular pulse shaping technique for large-diameter Kolsky bar experiments on concrete," Experimental Mechanics, vol. 54, no. 8, pp. 1343-1354, 2014.

[10] T. H. Lv, X. W. Chen, and G. Chen, "Analysis on the waveform features of the split Hopkinson pressure bar tests of plain concrete specimen," International Journal of Impact Engineering, vol. 103, pp. 107-123, 2017.

[11] X. Chen, L. Xu, and Q. Zhu, "Mechanical behavior and damage evolution for concrete subjected to multiple impact loading," KSCE Journal of Civil Engineering, vol. 21, no. 6, pp. 2351-2359, 2017.

[12] R. Merle and H. Zhao, "On the errors associated with the use of large diameter SHPB, correction for radially non-uniform distribution of stress and particle velocity in SHPB testing," International Journal of Impact Engineering, vol. 32, no. 12, pp. 1964-1980, 2006.

[13] R. Gerlach, S. K. Sathianathan, C. R. Siviour, and N. Petrinic, "A novel method for pulse shaping of Split Hopkinson tensile bar signals," International Journal of Impact Engineering, vol. 38, no. 12, pp. 976-980, 2011.

[14] R. Naghdabadi, M. J. Ashrafi, and J. Arghavani, "Experimental and numerical investigation of pulse-shaped split Hopkinson pressure bar test," Materials Science and Engineering A-structural Materials Properties Microstructure and Processing, vol. 539, pp. 285-293, 2012.

[15] Y. X. Zhou, K. Xia, X. B. Li et al., "Suggested methods for determining the dynamic strength parameters and mode-I fracture toughness of rock materials," International Journal of Rock Mechanics and Mining Sciences, vol. 49, no. 1, pp. 105-112, 2012.

[16] X. B. Li, Rock Dynamics: Fundamentals and Applications, Science Press, Beijing, China, 2014.

[17] P. Baranowski, J. Malachowski, R. Gieleta et al., "Numerical study for determination of pulse shaping design variables in SHPB apparatus," Bulletin of The Polish Academy of Sciencestechnical Sciences, vol. 61, no. 2, pp. 459-466, 2013.

[18] F. Q. Gong, X. L. Liu, and K. Gao, "Numerical simulation of the rational loading waveform in large diameter SHPB dynamic test for rock-like materials," Advanced Materials Research, vol. 243-249, pp. 2419-2422, 2011.

[19] F. Q. Gong, Experimental study of rock mechanical properties under coupled static-dynamic loads and dynamic strength criterion, Ph.D. thesis, Central South University, Changsha, China, 2010.

[20] A. Tyas and Z. Ozdemir, "On backward dispersion correction of Hopkinson pressure bar signals," Philosophical Transactions of the Royal Society A: Mathematical, Physical and Engineering Sciences, vol. 372, no. 2023, article 20130291, 2014. 


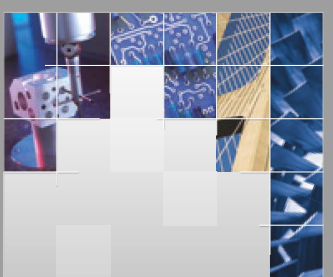

\section{Enfincering}
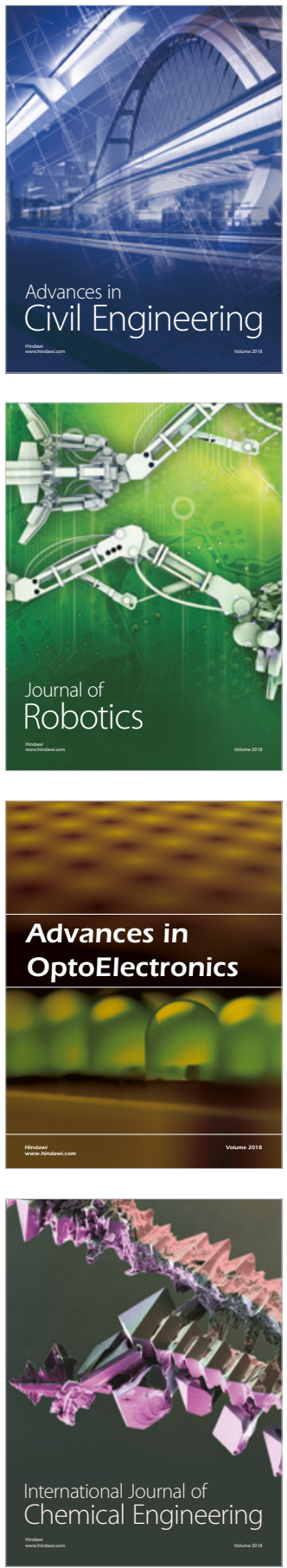

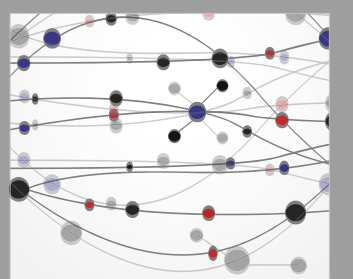

\section{Rotating \\ Machinery}

The Scientific World Journal

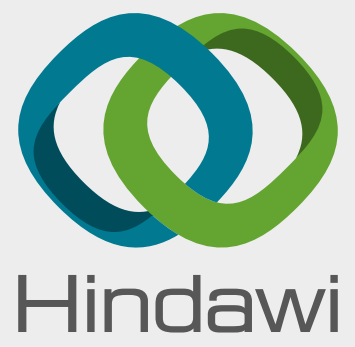

Submit your manuscripts at

www.hindawi.com
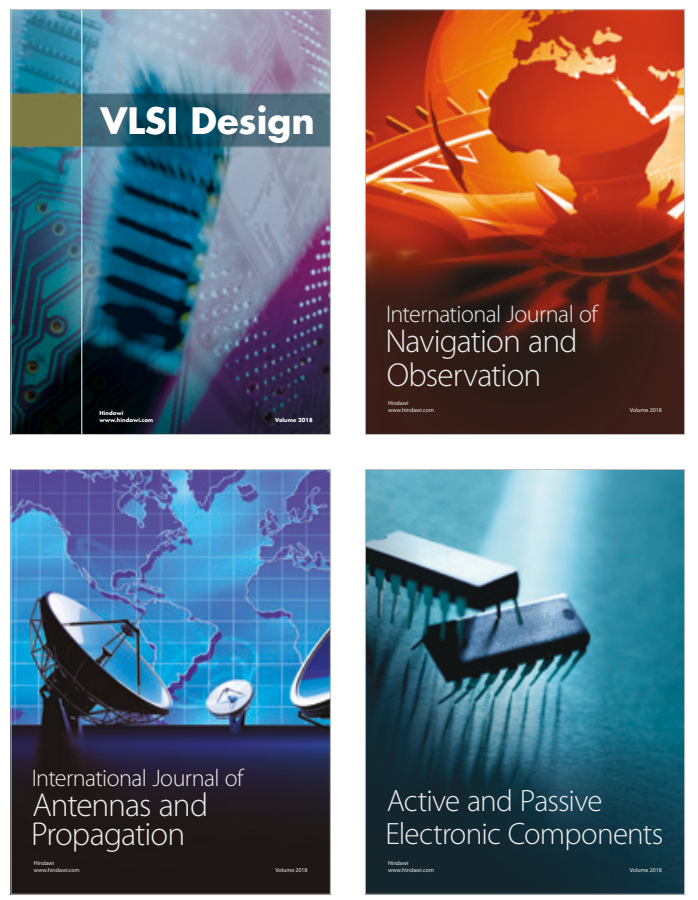
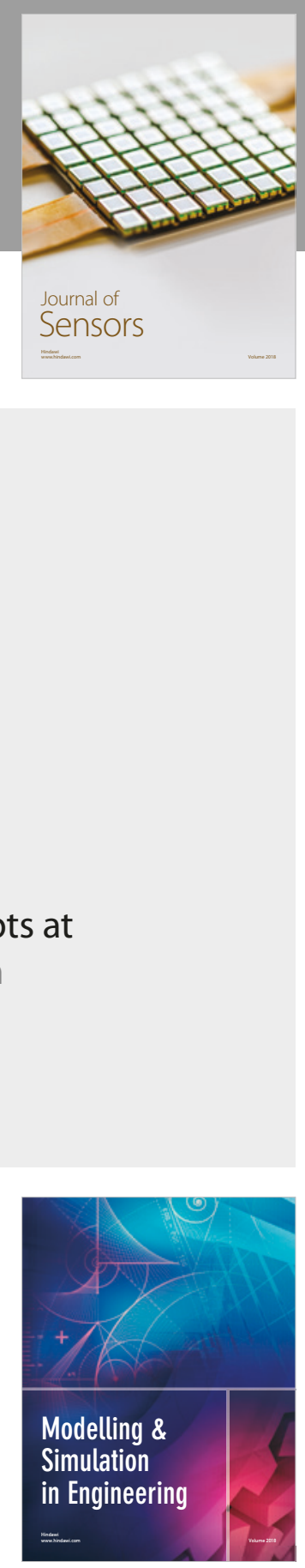

\section{Advances \\ Multimedia}
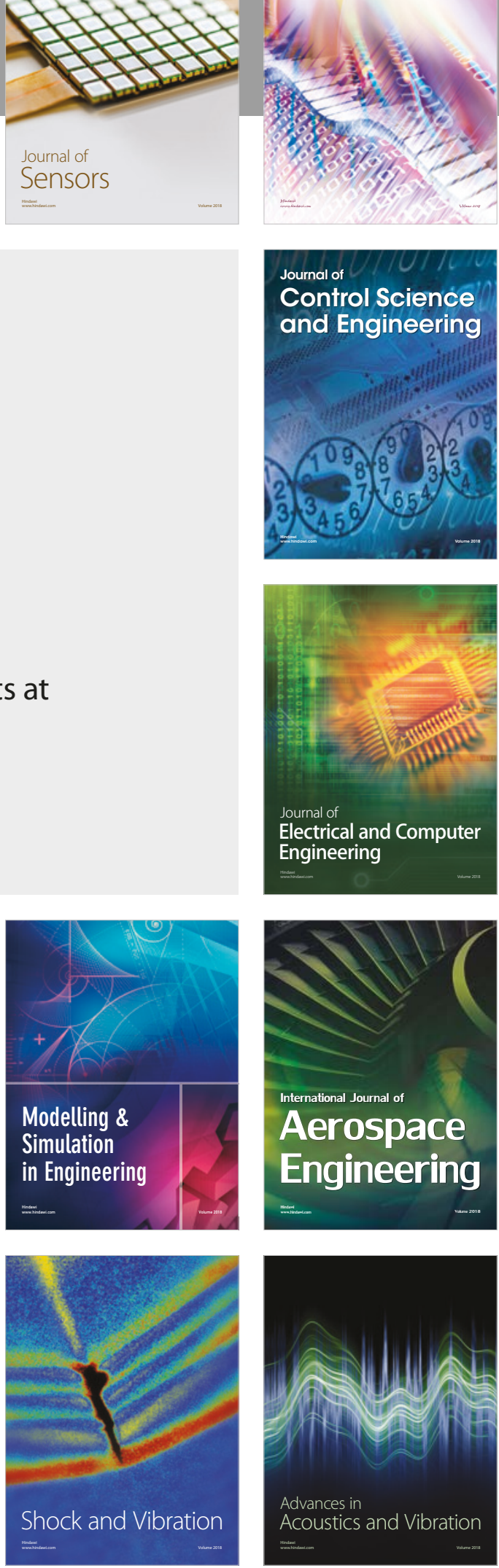